\title{
Origin and differentiation of microglia
}

\author{
Florent Ginhoux ${ }^{1 *}$, Shawn Lim ${ }^{2}$, Guillaume Hoeffel ${ }^{1}$, Donovan Low ${ }^{1}$ and Tara Huber ${ }^{2,3}$ \\ Singapore Immunology Network, Agency for Science, Technology, and Research, Singapore \\ ${ }^{2}$ Genome Institute Singapore, Agency for Science, Technology, and Research, Singapore \\ ${ }^{3}$ Department of Biological Science, National University of Singapore, Singapore
}

\section{Edited by:}

Amanda Sierra, University of the Basque Country EHU/UPV, Spain

Reviewed by:

Payam Rezaie, The Open

University, UK

Miguel A. Cuadros, Universidad

de Granada Spain, Spain

*Correspondence:

Florent Ginhoux, Singapore

Immunology Network,

8 A Biomedical Grove,

Immunos Building, Level 4,

Singapore, 138648

e-mail: florent_ginhoux@

immunol.a-star.edu.sg
Microglia are the resident macrophage population of the central nervous system (CNS). Adequate microglial function is crucial for a healthy CNS. Microglia are not only the first immune sentinels of infection, contributing to both innate and adaptive immune responses locally, but are also involved in the maintenance of brain homeostasis. Emerging data are showing new and fundamental roles for microglia in the control of neuronal proliferation and differentiation, as well as in the formation of synaptic connections. While microglia have been studied for decades, a long history of experimental misinterpretation meant that their true origins remained debated. However, recent studies on microglial origin indicate that these cells in fact arise early during development from progenitors in the embryonic yolk sac (YS) that seed the brain rudiment and, remarkably, appear to persist there into adulthood. Here, we review the history of microglial cells and discuss the latest advances in our understanding of their origin, differentiation, and homeostasis, which provides new insights into their roles in health and disease.

Keywords: microglia, macrophage, central nervous system, origin, yolk sac

\section{INTRODUCTION}

Microglia are the resident mononuclear phagocytes of the central nervous system (CNS), belonging to the glial system of non-neuronal cells that support and protect neuronal functions. Microglia are broadly distributed throughout the brain and the spinal cord (Lawson et al., 1990), and account for $5-20 \%$ of the total glial cell population within the CNS parenchyma (Perry, 1998). Adequate and appropriate microglial function is crucial for the homeostasis of the CNS in both health and disease (Perry et al., 2010).

There are two main functional aspects of microglia: immune defense and CNS maintenance. As immune cells, they act as sentinels, detecting the first signs of pathogenic invasion or tissue damage in this delicate immune-privileged site that is actively protected by the brain blood barrier (Daneman, 2012). Under the inflammatory conditions of an active immune response however, microglia must also moderate the potential damage to the CNS and support tissue repair and remodeling. Perhaps unsurprisingly, dysregulated microglial activation and microgliainduced inflammation is observed in virtually all brain pathologies; emerging evidence suggests that microglia exert direct effects on neurons, contributing to disease progression (Perry et al., 2010; Kettenmann et al., 2011; Kingwell, 2012).

In recent years there has been an increasing appreciation of the importance of microglia for normal CNS function. In addition to their immune functions, emerging data are showing new and fundamental roles for microglia in the control of neuronal proliferation and differentiation as well as in the formation of synaptic connections (Graeber, 2010; Hughes, 2012). In the steady state, microglial cells constantly survey their local microenvironment, extending their motile processes to make transient contact with neuronal synapses, contributing to the modification and the elimination of synaptic structures (Tremblay et al., 2010). Microglia also contribute to the remodeling of post-natal neural circuits as they have been recently shown to play a role in synaptic pruning during post-natal development in mice (Paolicelli et al., 2011).

Thus, microglia occupy a central position in the defense and maintenance of the CNS and so are attracting interest as potential therapeutic targets in neurological disorders and recovery from brain injury. However, in order to exploit the abilities of the microglial population, we must first understand their origins and homeostasis before attempting to manipulate their functions. In this review we will present the latest advances in our knowledge on the origin of microglia, revisit early studies in light of recent developments and highlight some of the most relevant strategies to generate microglia for therapeutic approaches of neurological disorders.

\section{HISTORICAL PERSPECTIVES ON THE NATURE OF MICROGLIA}

Defining the origin of microglia has been an elusive goal for generations of researchers and a longstanding issue of debate. Multiple schools of thought have emerged. The first description of the cells came from the work of Franz Nissl in the late nineteenth century, who described rod cells ("Stabchenzellen") as reactive glial elements with migratory, phagocytic and proliferative potential. In the late nineteenth century, W. Ford Robertson introduced the term "mesoglia" to describe mesoderm-derived phagocytic elements in the nervous system that had origins distinct from those of neurons and neuroglia. Neuroglia were first described by Virchow, in 1856, who named them "nevernkitt" meaning nerve-glue, later translated as "neuroglia," though in fact they corresponded to the macroglial population, which comprises astrocytes and oligodendrocytes (Rio-Hortega, 1939). While this 
idea had merit, in fact, Robertson's mesoglia similarly turned out to correspond mainly to oligodendrocytes. Santiago Ramon y Cajal later renamed the same cells the "third element of the nervous system" to further differentiate them from neurons and neuroglia, and stated that they were of probable mesodermal origin. This "third element" concept was refined further in 1919 by del Rio-Hortega, a student of Ramon y Cajal, who made the distinction between various cell types within the cells of the "third element" based on morphological and functional differences. Del Rio-Hortega introduced the term "microglial cell" to describe the non-neuronal, non-astrocytic third element as distinct from neurectodermal oligodendroglia or oligodendrocytes (Rio-Hortega, 1939) (For historic review see Rezaie and Male, 2002).

Although both W. Ford Robertson and Santiago Ramon y Cajal suspected a mesodermal origin of what were to become known as "microglial cells" (their mesoglia/third element of the nervous system), it was commonly held at the time that all glial cells were of neuro-ectodermal origin. Further dissecting the heterogeneity of the mesoglia, del Rio-Hortega was the first to introduce the term "microglia" to discriminate true mesodermal elements from oligodendrocytes, which were previously considered a component of the mesoglia. Del Rio-Hortega exploited silver staining techniques to describe the two types of cells as differing in origin, distribution, form, and function: the major population, called oligodendroglia, that lacked phagocytic activity, and the minor population of ramified resting cells. This minor population was then clearly defined as the "third element of the CNS" with a mesodermal origin, containing phagocytic corpuscles and with migratory and phagocytic activity (Rio-Hortega, 1932).

Despite del Rio-Hortega's seminal work, his theories were largely overlooked and have only recently come back to the forefront of scientific thinking (Rezaie and Male, 2002). At the time, there was much support for the belief that microglia shared a neuro-ectodermal origin with the other glial cells. Several studies supported this belief well into the twentieth century, including reports from Fujita who proposed a common, matrix-derived progenitor for microglia, astrocytes, and oligodendrocytes (Fujita and Kitamura, 1975). The work of Kitamura was similarly interpreted to indicate that microglia, as well as astrocytes, originated from neuro-ectodermal-derived glioblasts (Kitamura et al., 1984). As late as the 1990's, new studies continued to emerge that seemed to show a common origin of astrocytes and microglia; Hao reported that cultures of either murine embryonic neuroepithelial cells or astrocytes could differentiate in vitro to give microglial-like cells, an idea which was supported by Fedoroff's work showing that clonal cultures of disaggregated neopallial cells from newborn mice gave rise to mixed microglial-astroglial cells (Hao et al., 1991; Fedoroff et al., 1997). In addition, data showing that donor bone marrow cells failed to contribute to the adult microglial population in either newborn (De Groot et al., 1992) or adult rodents (Matsumoto and Fujiwara, 1987) was interpreted to mean that the majority of microglial cells were of local neuroectodermal origin. However, this interpretation was soon updated in response to the finding that microglia (in contrast to other blood leucocyte populations) are highly radio-resistant. In 1993,
Lassmann and co-workers were the first to demonstrate that resident microglia in rats are a very stable cell pool, in contrast to meningeal and perivascular macrophages, which in adult animals are only exceptionally replaced by circulating blood cells, even after recovery from severe brain inflammation (Lassmann et al., 1993). Such observations were later confirmed in mice by Priller, where the majority (85-95\%) of microglial cells remained of host origin up to 15 weeks after bone marrow transplantation (Priller et al., 2001). The importance of the observation that newborn microglia are not replaced by donor bone marrow-derived cells (De Groot et al., 1992) will be discussed later, as it has the significant implication that the adult microglial population can be maintained solely by local radio-resistant precursors which are present in the brain prior to birth.

Other hypotheses on the origin of microglia included their derivation from the pericytes associated with blood vessels (Mori and Leblond, 1969; Baron and Gallego, 1972) or from the subependyma adjacent to the lateral ventricles (Lewis, 1968).

At the same time, a second school of thought was developing which paralleled del Rio-Hortega's original hypothesis. His conviction of the mesodermal origin of microglia was supported both by studies coupling light/electron microscopy and immunohistochemistry, which recognized typical morphological features of macrophages in the various stages of microglial development (Murabe and Sano, 1982), and by the demonstration that microglial cells reacted positively to antisera recognizing monocyte/macrophage antigens (Hume et al., 1983; Murabe and Sano, 1983). Despite the emerging evidence of the relationship of microglia to macrophages, other reports led to variable interpretations due to a lack of homology between monocytes and mature microglia in the expression of certain antigens, complicating the issue (Oehmichen et al., 1979; Wood et al., 1979). Nevertheless, the data showing phenotypic homologies between monocytes/macrophages and microglia were eventually validated by immunohistochemical studies that reported the specific expression of macrophage markers, including F4/80, Fc receptor and CD11b in mouse microglia (Perry et al., 1985), as well as FcGRI, and CD11b in their human counterparts (Akiyama and McGeer, 1990). Finally, a pivotal genetic study revealed that mice lacking PU.1, a crucial transcription factor for myeloid cells, were also devoid of microglia (McKercher et al., 1996; Beers et al., 2006). This unequivocally established the myeloid nature of microglia and simultaneously suggested that these cells might be ontogenetically related to macrophages.

\section{THE ORIGIN(S) OF MURINE MICROGLIA}

Although there is a consensus about the myeloid origin of microglia, much controversy remains regarding the precise nature of microglial progenitors. Initial studies described the presence of microglial cells during early development, suggesting that microglia arise from embryonic progenitors. While del Rio-Hortega proposed that microglia originate from meningeal macrophages penetrating the brain during embryonic development, many authors including del Rio-Hortega himself, claimed that brain parenchymal microglia could also be derived from blood monocytes. Monocytes are indeed recruited to the neonatal and adult brain, in the latter case most often under inflammatory 
conditions, where they can differentiate into microglia-like cells. This knowledge long supported the prevailing viewpoint that circulating blood monocytes represent microglial progenitors, replacing those seeding the brain during embryonic development. In fact, until recently, the most consensual hypothesis was that embryonic and peri-natal hematopoietic waves of microglial recruitment and differentiation occurred in the CNS (Chan et al., 2007). However, we now know that the situation is somewhat different. Here, we will describe and discuss the recent advances in understanding of the origin of microglia, and will also revisit the data from earlier studies in light of these developments.

\section{EARLY DEVELOPMENT}

In addition to having first described microglia, del Rio-Hortega also proposed that they might initially arise in the early stages of development from mesodermal cells of the pia mater, the innermost layer of the meninges (the membranes surrounding the brain and spinal cord). From his work on embryonic brains, he reported the "migration of embryonic corpuscles from the pia into the nerve centers" with morphological similarity to lymphocytes (Rio-Hortega, 1939). However, del Rio-Hortega also proposed that "microglia may eventually arise from other related elements, chiefly the blood mononuclears" based on the similarities in morphology and phagocytic activities of the microglia and monocytes (Rio-Hortega, 1939), thereby founding the "origin of microglia" controversy.

The immunohistochemical study conducted by Perry et al., more precisely described this phenomenon using macrophage markers such as F4/80. They concluded that as early as embryonic day 16 (E16) of development, macrophage-like cells that had extravasated into the brain parenchyma were localized in "hot spots," from where they subsequently invaded the brain and differentiated through a series of transitional forms to finally become ramified microglia (Perry et al., 1985). Other studies later detected dispersed F4/80 expressing macrophages distributed within loose connective tissue surrounding the neuroectoderm in E12 rat embryos (Morris et al., 1991). Also in the rat, amoeboid microglial cells expressing monocytic markers are present as early as E12 in the neuro-epithelium (Wang et al., 1996). Interestingly, such embryonic cells were proposed to be microglial progenitors not only due to the similarities in phenotype and morphology, but because of their potent proliferative response to mitogenic stimulation in vitro (Alliot et al., 1991).

Similarly, in human fetuses, microglia-like cells with a range of morphologies can be detected from as early as 3 weeks of estimated gestational age (EGA) (Hutchins et al., 1990). However, it appears that maturation of the microglial compartment is ongoing throughout the majority of gestation: colonization of the spinal cord begins at around 9 weeks, the major influx and distribution of microglia commences at about 16 weeks, and ramified microglial forms take up to 22 weeks to become widely distributed within the intermediate zone (Rezaie and Male, 1999; Rezaie et al., 2005). It is only close to term, at 35 weeks, that well-differentiated microglial populations can be detected (Esiri et al., 1991) (for review Rezaie, 2003 and Verney et al., 2010).
Altogether, these seminal studies strongly suggested that microglia derive from embryonic hematopoietic precursors that seed the CNS prior to birth and, more importantly, before the onset of bone marrow hematopoiesis. However, the exact tissue origin and developmental cell lineage of precursors that migrate to the CNS to give rise to the "first" endogenous wave of microglia remained unknown and a topic of debate until recently.

\section{MOUSE AND HUMAN EMBRYONIC HEMATOPOIESIS}

A major challenge in defining the embryonic microglial precursor was the complication of the dual source of blood cell formation during embryogenesis. Two major hematopoietic sites contribute to this process: the extra-embryonic yolk sac (YS) and the fetal liver (Tavian and Peault, 2005; Orkin and Zon, 2008). In mice, primitive hematopoiesis initiates in the YS around E7.0, shortly after the onset of gastrulation, leading mainly to the production of erythrocytes and macrophages (Moore and Metcalf, 1970; Palis et al., 1999; Bertrand et al., 2005). Primitive macrophages first appear in the blood islands of the mouse YS on the ninth day of gestation and their pattern of differentiation is unique in the sense that they do not go through a monocytic intermediate stage, as seen in adult macrophages (Takahashi et al., 1989). YS-derived primitive macrophages will spread into the embryo proper through the blood after the circulatory system has been fully established (from E8.5 to E10) (McGrath et al., 2003) and migrate to various tissues, including the brain. Once in the tissues, they differentiate into so-called "fetal macrophage populations" even before the onset of monocyte production by the fetal liver (Naito et al., 1990). These fetal macrophages have high proliferative potential, not only in the YS where they are produced but also in the tissues that they colonize (Takahashi et al., 1989; Sorokin et al., 1992; Naito et al., 1996; Lichanska and Hume, 2000). After E8.5, with the determination of the intra-embryonic mesoderm toward the hematopoietic lineage, a new wave of hematopoietic progenitors is generated within the embryo proper, first in the para-aortic splanchnopleura (P-Sp) region and then in the aorta, gonads, and mesonephros (AGM) region (Godin et al., 1993; Medvinsky et al., 1993). The hematopoietic stem cells generated within the AGM will lead to the establishment of definitive hematopoiesis (Orkin and Zon, 2008). Around E10.5, YS- and AGM-derived hematopoietic progenitors colonize the fetal liver (Kumaravelu et al., 2002), which serves as the major hematopoietic organ after E11.5, generating all hematopoietic lineages, including monocytes (Naito et al., 1990). A recent study highlighted further differences between primitive and definitive hematopoiesis, showing that the latter relies on the transcription factor Myb, while YS-derived macrophages are Myb-independent. This further underlines the fact that YSderived macrophages constitute an independent lineage, distinct from the progeny of definitive hematopoietic stem cells (Schulz et al., 2012).

Human hematopoiesis also begins in the YS around day 19 of the EGA, and YS-derived stem cells are similarly limited/committed to myelo-erythroid development. Hematopoiesis then moves transitorily to the fetal liver around 4-5 weeks EGA, before being definitively established in the BM approximately at 10.5 weeks EGA (Tavian and Peault, 2005). 


\section{THE YOLK SAC HYPOTHESIS OF MICROGLIAL ORIGIN}

Ashwell was the first to report the presence of round and amoeboid microglial cells in the fetal mouse cerebellum (Ashwell, 1990) and then in rat forebrain (Ashwell and Waite, 1991) as early as E11.0. Sorokin soon after detected macrophage-like cells and their precursors in blood vessels and the embryonic mesenchyme in rat embryos from 10.5, and noted that the developing brain was the first organ to be colonized (Sorokin et al., 1992). Interestingly, cells with the capacity to differentiate into microglia-like cells in vitro (expressing Mac-1, Mac-3, F4/80 and $\mathrm{Fc}$ antigens, with a macrophage-like morphology and ultrastructure) can be detected in the developing neuro-epithelium at days E8.5/E9.0, suggesting that in mice, the earliest developmental stage at which seeding of cells with myeloid features occurs in the brain is at E8.5/E9.0 (Alliot et al., 1991). Later reports confirmed the presence at similar stages of amoeboid cells expressing macrophage (Alliot et al., 1999; Ginhoux et al., 2010) and microglial markers (Chan et al., 2007; Mizutani et al., 2012) in both the cephalic mesenchyme and the neuro-epithelium, in accordance with the idea that the YS contributes to microglial genesis.

However, the evidence for a YS origin of such microglial progenitors was, at first, mixed. Initially, data from one of the aforementioned in vitro studies were interpreted to support the hypothesis that these macrophage-like cells that will give rise to microglia originated from the neuro-ectoderm (Hao et al., 1991). Takashi and Naito drew a different conclusion after they described the first emergence of immature macrophages within blood islands of embryonic YS at fetal day 9 in both mouse (Takahashi et al., 1989) and rat (Takahashi and Naito, 1993). Following the establishment of fetal blood circulation, these cells colonize the embryonic tissues, including the brain rudiment. By $[3 \mathrm{H}]$-thymidine autoradiography, YS macrophages were shown to possess high proliferative potential, which suggested that these fetal macrophages were in fact primitive macrophages from the YS (Takahashi and Naito, 1993). Alliot also clearly and convincingly proposed that such cells were true microglial progenitors of YS origin, as, at that stage, the YS is the only hematopoietic site in the embryo. This group then conclusively documented the presence of potential microglial progenitors in the YS and then the brain rudiment, with their numbers increasing dramatically from E9.0/E9.5 until around 2 weeks after birth (Alliot et al., 1999).

A similar pattern of events is likely observed in humans, where, from 4.5 weeks gestation, amoeboid microglial cells (characterized by the expression of Iba1, CD68, CD45, and MHC-II) enter the cerebral wall from the ventricular lumen and the leptomeninges (Rezaie et al., 2005; Monier et al., 2007). In the YS and mesenchyme at 4-6 weeks after fertilization, two populations of cells with a dendritic morphology could be distinguished: a majority that expressed monocyte/macrophage-associated markers but no detectable HLA-DR antigen, while the minority constitutively expressed MHC class II (HLA-DR and -DP) but no monocyte/macrophage-associated markers (Janossy et al., 1986). The emergence of this heterogeneity preceded the formation of both thymus and bone marrow, suggesting the independent development of these macrophage populations (for review Verney et al., 2010).
Interestingly, the YS derivation of microglia appears to be conserved across diverse species as shown in the zebrafish (Herbomel et al., 2001), and in avians (Cuadros and Navascues, 1998). However, what differs in mice is the requirement for a functional blood circulation for the spreading of YS macrophages in the embryo proper. In zebrafish, this colonization appears independent of the blood circulation as YS macrophages first directly invade the whole cephalic mesenchyme, and from there invade epithelial tissues including the brain, while other macrophages enter the blood circulation (Herbomel et al., 1999). Similarly, using chick-quail blood chimeras, Kurz showed that in avians, YS macrophages do not penetrate through the wall of embryonic CNS vessels, but rather from the pial surface (Kurz et al., 2001). In contrast, in mouse embryos, there is a clear requirement for the circulatory system as E9.5-E10.5 $\mathrm{Ncx}-1^{-/-}$embryos, which lack a heartbeat and therefore have no functional blood circulation due to a defect in the sodium calcium exchanger 1 (Koushik et al., 2001), also lack microglial progenitors (Ginhoux et al., 2010), as well as other fetal macrophages. However, this defect does not affect YS hematopoiesis as $N c x-1^{-/-}$embryos have similar numbers of YS macrophages as their control, normal phenotype littermates (Ginhoux et al., 2010). Whether murine YS macrophages enter via the blood circulation directly in the brain parenchyma or first enter in the cephalic mesenchyme and then migrate to the neuro-epithelium (Chan et al., 2007) remains to be clearly defined.

The overall conclusion of these studies in rodents, humans, and other species is that microglia derive from the YS macrophages that seed the brain rudiment during early fetal development (Figure 1). However, these reports could not exclude the possibility that others progenitors could supersede the YS contribution. In fact, some data that will be discussed below, continued to emerge that suggested a requirement for the contribution of blood-borne cells to both generate the post-natal microglial compartment, and to maintain it into adulthood.

\section{THE EARLY POST-NATAL CONTRIBUTION OF MONOCYTES TO THE MICROGLIAL POPULATION}

Shortly after birth in rodents, the microglial population expands dramatically (Alliot et al., 1999; Tambuyzer et al., 2009), leading to the suggestion that the proliferation of embryonic microglial cells alone could not account for the steep rise in numbers and that there must be a fresh influx of cells from another compartment. As initially suggested by del Rio-Hortega, blood monocytes were believed to invade the CNS in the perinatal period and give rise to microglia, replacing the embryonic microglial cells.

There was support for this belief from several studies, notably an early report where round, amoeboid, phagocytic cells were seen in rat corpus callosum during the first few days of life and then disappeared coincident with the appearance of ramified microglia. These cells were typical macrophages, but some displayed features of monocytes, while others appeared to be transitional between the two types. The authors of this study concluded that circulating monocytes enter the developing brain to assume the form of ameboid microglia that subsequently evolved to become ramified microglia (Ling, 1976). Subsequent studies gave neonatal rats an intra-peritoneal pulse of [3H]-thymidine to 


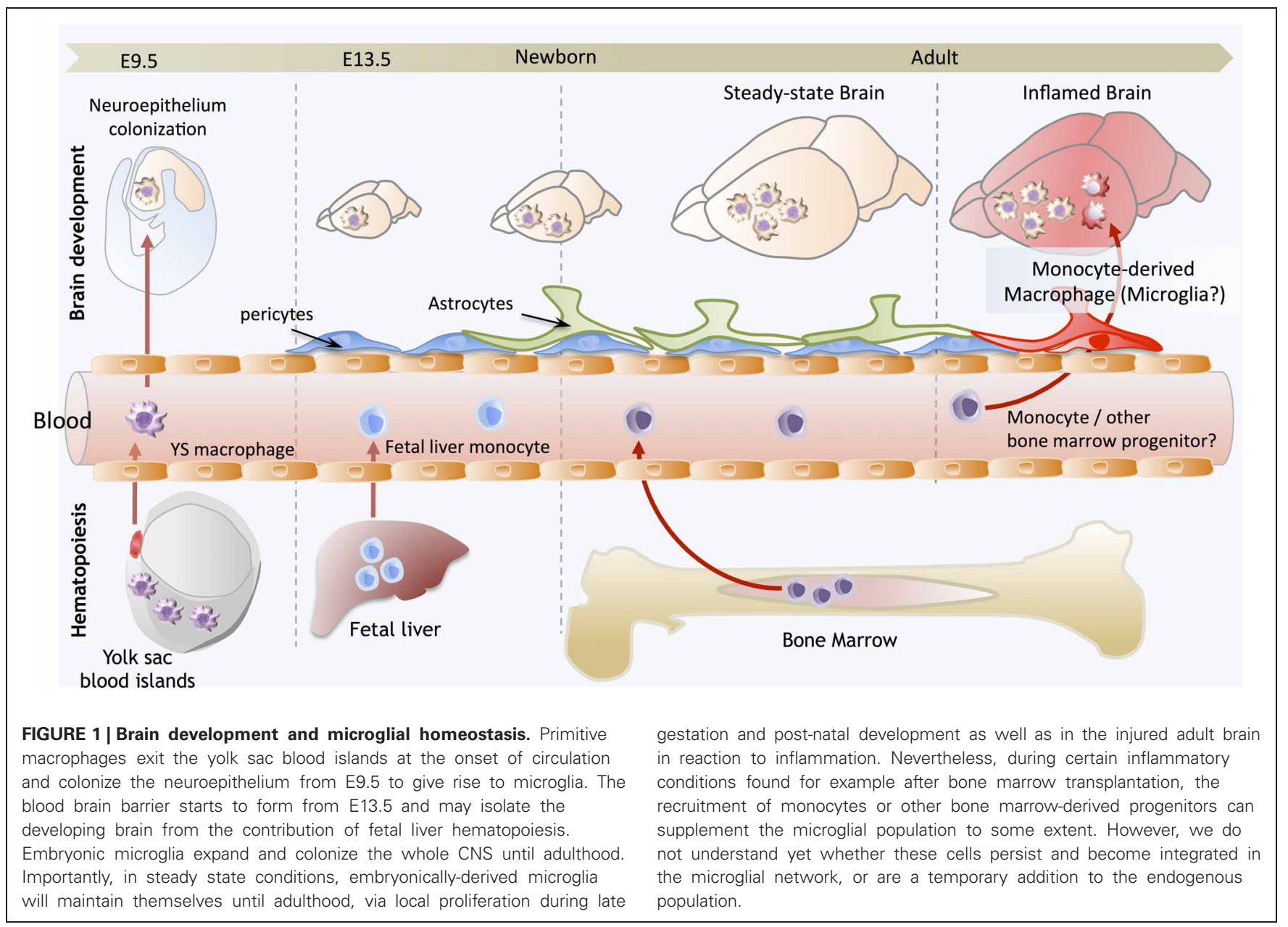

allow tracking of labeled blood cells by autoradiography. Labeled immature amoeboid cells were detected in the corpus callosum few hours after administration, while the majority of newlyramified microglia were labeled one week later. These observations implied that labeled microglial cells must therefore have come from the transformation of immature amoeboid cells that acquired the tracer earlier (Imamoto and Leblond, 1978). This possibility was further tested by injecting a suspension of carbon particles into the circulation of rats of various ages to enable tracing of carbon-labeled monocytes, or by direct adoptive transfer of carbon-labeled monocytes. Later on, carbon particles were sequentially found in amoeboid cells of the corpus callosum and then on ramified microglial cells, suggesting again that blood monocytes, after ingesting carbon particles in the circulation or after transfer, migrated to the corpus callosum and differentiated into microglial cells via an amoeboid stage (Ling, 1979; Ling et al., 1980; Leong and Ling, 1992). However, while such data suggest that circulating blood monocytes can enter the CNS right after birth, perhaps in a specific site, it is important to note that such studies were rather qualitative and did not clearly address the exact relative contributions of post-natal monocytes versus embryonic progenitors to adult microglial homeostasis. In fact, the authors had themselves clearly recognized that such events were infrequent (Ling et al., 1980).
Nevertheless, later studies employing the PU.1 knockout (KO) mouse model, that lacks embryonic microglia, demonstrated the capacity of bone marrow-derived cells to contribute to the post-natal microglial population. In this study, neonates received wild-type bone marrow transplants within $24 \mathrm{~h}$ of birth, which resulted in de novo generation of the full microglial compartment (Beers et al., 2006). Therefore, it must be concluded that, at least under exceptional circumstances such as in the PU.1 KO mouse where endogenous embryonic microglia are completely absent, some bone marrow-derived cells have the capacity to infiltrate the CNS and assume the morphology and phagocytic capacity of microglia.

\section{A CONTRIBUTION OF MONOCYTES TO THE ADULT MICROGLIAL POPULATION IN THE STEADY STATE?}

Following the observations that monocytes might be able to contribute to the microglial population immediately after birth, it became implicitly accepted that they could also do so in adults. The idea that monocytes, or any bone marrow-derived cells, might then be able to be engineered and used as a delivery system into the CNS for therapies, the "Trojan Horse" theory, motivated investigators to discover the underlying mechanisms. The main hypothesis became that embryonic microglia disappear and are replaced by post-natal bone marrow-derived cells. 
That is not to say that there were not data supporting the hypothesis of a role of monocytes in maintaining the adult microglial population: a seminal study employing $[3 \mathrm{H}]-$ thymidine incorporation and autoradiography in normal adult mice concluded that cells can be recruited from the circulating monocyte pool through an intact blood-brain barrier (BBB) and rapidly differentiate into resident microglia (Lawson et al., 1992). However, the authors also noted that the resident microglia were proliferating, which suggested that the microglial population might maintain itself through either mechanism, or perhaps both. Other data supporting the idea that adult bone marrowderived cells can give rise to microglia included the observation that following total bone marrow transplantation, some donor hematopoietic cells differentiated into microglia within the brains of adult mice (Eglitis and Mezey, 1997; Mezey et al., 2000; Simard and Rivest, 2004).

However, these results were in slight disagreement with a previous, and importantly, more quantitative, study which showed that the majority of microglial cells remained of host origin up to 15 weeks after bone marrow transplantation in mice (Priller et al., 2001). Similar results were also initially reported in rats as several investigators concluded that there was little or no contribution of bone marrow-derived cells to the adult microglial pool (Matsumoto and Fujiwara, 1987; Lassmann et al., 1993). In addition, it was shown that while microglia are not bone marrowderived in adults, the closely-associated meningeal and perivascular macrophages are, perhaps going some way to explaining the confusion. Schelper and Adrian bluntly concluded that "monocytes become macrophages; they do not become microglia," in this case, following CNS lesions (Schelper and Adrian, 1986), while Hickey and Kimura showed that the stable pool of resident microglia is only exceptionally supplemented by hematopoietic cells, even after recovery from severe brain inflammation (Hickey and Kimura, 1988). Similarly, Vallieres reported that many of these cells were in fact perivascular macrophages and that newly-formed parenchymal microglia were found in significant numbers only in the cerebellum and at injury sites (Vallieres and Sawchenko, 2003). Importantly, in humans, taking advantage of sex-mismatched donor bone marrow transplant (male into female) where Y-chromosome specific in situ hybridization can be performed to follow the origin of cells, similar results were obtained. The only donor male cells detected corresponded to mononuclear leucocytes within the vessel lumen and infiltrating the perivascular space and parenchyma, and perivascular cells (Unger et al., 1993). In fact, the observation that bone marrowderived microglia were only found in notable amounts under certain conditions highlighted some significant shortfalls of the earlier studies: while it was successfully shown that monocytes could differentiate into cells that resembled microglia, few had quantified the effect or attempted to define the phenomenon in space and time, or to monitor the persistence of the bone marrow-derived microglia.

\section{A CONTRIBUTION OF MONOCYTES TO THE ADULT MICROGLIAL POPULATION DURING INFLAMMATION?}

What became clear was that although the monocyte-to-microglia path may exist in adult brain, it is unlikely to be a significant source for maintaining the microglial population, although this might change during CNS inflammation or disease (Vallieres and Sawchenko, 2003; Ladeby et al., 2005; Mildner et al., 2007). In fact, in response to CNS inflammation and damage, an increase in microglial number is often observed, a phenomenon called reactive microgliosis, which has become a hallmark of many CNS pathologies. However, it remained to be elucidated whether such increases in number rely on local expansion of mature microglia or are achieved by recruitment of blood precursors such as monocytes.

Two recent studies clarified the relative contribution of blood monocytes to microglia in experimental models of CNS pathologies. Both revealed that the irradiation regimen used to prepare recipient animals for bone marrow transplants is necessary for the recruitment and differentiation of monocytes into microglia (Ajami et al., 2007; Mildner et al., 2007). Mildner showed that recipient mice in which the CNS was shielded to protect from the irradiation and its associated inflammation, which induces the release of pro-inflammatory cytokines and chemokines, did not experience a significant invasion of bone marrow-derived cells into the brain, in contrast to the unshielded mice (Mildner et al., 2007). Beyond the irradiation issue, these data also suggest that microglial engraftment from the blood requires pre-conditioning of the CNS that likely disrupts the BBB. Additional clarity came from experiments in parabiotic mice, which have undergone surgery to physically link their circulatory systems, providing a more physiological means to study the turnover of hematopoietic cells for prolonged periods without the need for irradiation (Ajami et al., 2007). Ajami used such mice to show that in contrast to what was observed in irradiated and transplanted mice, there was no microglial progenitor recruitment from the circulation in either denervation or CNS neurodegenerative disease, despite the fact that the mixing of leucocyte populations can reach up to $50 \%$ in the blood of both parabionts. In agreement with their findings, we found no contribution of bone marrow-derived cells to CNS microglia up to 12 months after parabiosis (Ginhoux et al., 2010). Such data suggest that maintenance and local expansion of microglia are solely dependent on the self-renewal of CNS-resident cells in these models.

Interestingly, with this parabiotic model, in the context of irradiation of one parabiont, no further contribution from the other parabiont was detected in contradiction with the results of Mildner. However, Ajami further clarified that although irradiation is required for donor cells to engraft, it is not sufficient; another important, but overlooked, requirement is the artificial introduction of a critical number of bone marrow cells into the blood circulation (where they are not normally found) in conjunction with the inflammation of BBB caused by irradiation, a situation found only upon lethal total bone marrow transplantation (Diserbo et al., 2002; Li et al., 2004; Linard et al., 2004). More recently, the same group used a similar approach combining parabiosis and myelo-ablation to show that recruited monocytes do not persist and therefore do not contribute to the resident microglial pool. However, recruited monocytes contribute to the severity of disease in multiple sclerosis and the experimental autoimmune encephalitis mouse model (Ajami et al., 2011). Similarly, in transgenic mouse models of Alzheimer's disease, 
irradiation was shown to condition the brain for engraftment of myeloid cells, a phenomenon that does not occur normally during disease progression (Mildner et al., 2011). Interestingly, in this study, perivascular macrophages, rather than microglia and monocytes, modulated $\beta$-amyloid deposition in the brains of $\mathrm{AD}$ transgenic mice by clearing $\mathrm{A} \beta$ in a CCR2-dependent fashion (Mildner et al., 2011). This highlights the distinct and non-redundant roles of microglia, monocyte, and perivascular macrophages in acute injury and autoimmune inflammation (Jung and Schwartz, 2012). Finally, Capotondo recently clarified that the conditioning regimen also contributes to the ablation of endogenous microglia, thereby allowing the local proliferation of invading blood cells (Capotondo et al., 2012). In conclusion, parabiotic mice provided, for the first time, unequivocal evidence that the microglial population during the steady state is able to maintain itself throughout adult life by local renewal, independent of circulating precursors in steady state. Conversely, in transplant models, which are perhaps not so much reflections of normal physiology, a fraction of microglia can arise from adult bone marrow.

As discussed before, we know that adult bone marrow cells can also enter into the CNS and differentiate into microglia in exceptional circumstances: when the endogenous microglial niche is completely vacant, such as in the PU.1 KO (Beers et al., 2006), or experimentally depleted, for example using Gancyclovir in a mouse model expressing the thymidine kinase under the CD11b promoter (Varvel et al., 2012). Importantly, microglial repopulation in the latter study did not require any conditioning regimen such as irradiation, as the microglial pool reconstituted itself after cessation of the Gancyclovir treatment. However, the effect of Gancyclovir on the permeability of the BBB was not evaluated in this model and we do not know if the bone marrow progenitors require additional "help" in order to cross the BBB, perhaps through the presence of as yet undefined inflammatory mediators. In addition, in their experimental setting, the authors could not formally track the origin of the cells that repopulate the microglia and therefore were unable to exclude local repopulation from non-depleted microglial cells. Nevertheless, the fact that adult bone marrow cells can give rise to microglia in the context of hematopoietic cell transplantation with a conditioning regimen open the door for invaluable therapeutic strategies for the correction of CNS conditions in which defects of microglia are implicated. For example, bone marrow transplantation of mouse models for metachromatic leukodystrophy (Biffi et al., 2004), the obsessive compulsive disorder trichotillomania (Chen et al., 2010), and Rett syndrome (Derecki et al., 2012) has been shown to ameliorate disease symptoms.

In conclusion, in these transplant models, which are perhaps not so much reflections of normal physiology, a fraction of microglia are of bone marrow origin. However, during the steady state, monocytes or other bone marrow-derived cells do not enter the CNS and do not significantly contribute to the microglial population.

\section{EVIDENCE FOR THE PERSISTENCE OF THE EMBRYONIC WAVE OF MICROGLIA}

What remained unclear in the field, however, was the relative contribution of embryonic and post-natal hematopoietic progenitors to the steady-state microglial population in adults: are the embryonic microglia responsible for maintaining the adult pool or do embryonic and adult microglia in fact have different origins? One of the studies already discussed, from De Groot, had implied that embryonic microglia were the sole contributors to the adult microglial pool. This study observed that donor bone marrow cells failed to contribute to the adult microglial population in a model of newborn transplantation, and concluded therefore that the adult microglial population was totally independent of post-natal bone marrow-derived circulating precursors from birth onward (De Groot et al., 1992). Recently, we revisited their experiments with a more quantitative aim and found that while most circulating leucocytes were of donor origin, the majority of microglia remained of host origin for more than 3 months after transplantation, confirming that post-natal hematopoietic precursors, including monocytes, likely do not contribute to the adult microglial population (Ginhoux et al., 2010).

We also employed a more advanced technique of YS progenitor fate mapping to definitively answer this question. Our fate mapping mouse model expresses a fluorescent protein (eYFP) exclusively in YS progenitors and their progeny, which include YS macrophages. Briefly, this mouse model expresses a tamoxifenactivated MER-Cre-MER recombinase gene under the control of one of the endogenous promoters of the runt-related transcription factor 1 (Runx1) locus (Samokhvalov et al., 2007). When crossed with a Cre-reporter mouse strain, recombination can be induced in embryos by a single injection of 4-Hydroxytamoxifen $\left(4^{\prime} \mathrm{OHT}\right)$ into pregnant females. Active recombination in these knock-in mice occurs in a short time frame that does not exceed $24 \mathrm{~h}$ post-injection and leads to irreversible expression of eYFP in Runx1 ${ }^{+}$cells and their progeny (Samokhvalov et al., 2007).

Although both YS and fetal liver hematopoietic progenitors express Runx1, YS progenitors are the only cells present at E7.5 and so injection of tamoxifen at E7.5 will therefore allow the specific and irreversible tagging of YS progenitors and their progeny but not of fetal liver-derived progeny. In contrast, injection of tamoxifen at later time points (from E8.5) will favor the tagging of AGM-derived hematopoietic progenitors and not the YS progenitors (North et al., 1999; Samokhvalov et al., 2007). We can use this model to accurately ask about the origins of different cell types; for example, in the case of microglia, if they are predominantly derived from YS tagged progenitors, they should express eYFP in the adult CNS when $4^{\prime} \mathrm{OHT}$ is injected at E7.5 and not at E8.5. In contrast, circulating leukocytes, including monocytes that are known to derive from AGM hematopoietic progenitors, will present the opposite profile, expressing eYFP when $4^{\prime} \mathrm{OHT}$ is injected at E8.5 instead of E7.5. In addition, if the microglial population does predominantly derive from YS progenitors without a significant contribution from fetal liver- or bone marrow-derived hematopoiesis, they should be tagged at a higher level than circulating leukocytes, which derive predominantly from mature hematopoiesis. To test this hypothesis, we injected the mice with tamoxifen at closely spaced time points of gestation and compared the number of eYFP-tagged microglia and circulating monocytes in the mice as adults. Strikingly, the relative number of tagged microglia in mice injected at E7.25 was much greater than of 
blood monocytes or other circulating leukocytes (Ginhoux et al., 2010).

In contrast, the relative number of tagged microglia in mice injected from E8.0 onwards decreased dramatically to reach undetectable levels as soon as E8.5, while the relative number of $e \mathrm{YFP}^{+}$leukocytes, including monocytes, increased progressively in adult blood. This opposing pattern of recombination in microglia compared to circulating leukocytes strongly supports the idea that the major contribution to microglial numbers comes from YS progenitors, and formally excludes the contribution of definitive hematopoiesis. Altogether these results establish that microglia originate from E7.25 Runx1 YS-derived hematopoietic progenitors, with little, if any, contribution from hematopoietic progenitors arising later in embryonic development. Recent studies confirmed our findings (Schulz et al., 2012; Kierdorf et al., 2013). In particular, the latest study from Kierdorf refined the characterization of the YS precursors that give rise to microglia and identified them as early E8 primitive c-kit ${ }^{+}$erythromyeloid YS precursors which develop into $\mathrm{CD}_{4} 5^{+} \mathrm{c}$-kitloCX3CR1 ${ }^{-}$cells before their maturation and migration into the developing brain as $\mathrm{CD} 45^{+}$c-kit-CX3CR1 ${ }^{+}$cells (Kierdorf et al., 2013).

Altogether, these studies conclusively demonstrated that primitive macrophages are the embryonic source of the steady-state adult microglial population, which was particularly interesting as it implied that microglia not only have a unique functional specialization within the CNS, but also a unique origin, arising from YS progenitors that maintain themselves by proliferating in situ throughout adulthood (Figure 1). Beyond the case of microglia, it also provided startling evidence for a broader conclusion, that primitive macrophages are the ultimate source of a functional immune compartment that persists throughout adulthood. However, the case of the microglia seems to be unique, as other fetal macrophage populations in the embryo will mostly be replaced by fetal liver-derived monocytes that seed the tissues later and differentiate into macrophages, as we have recently shown in the case of Langerhans cells (Hoeffel et al., 2012). Lack of differentiation of fetal liverderived monocytes into microglial progenitors could result from their lack of intrinsic differentiation potential or lack of access to the developing brain. Corroborating the latter hypothesis, the $\mathrm{BBB}$ in rodents is starting to be established at approximately E13.5, at the time of fetal liver monocyte release into the blood circulation (Daneman et al., 2010), but after YS-derived macrophages start to invade the neuro-epithelium from E9.5 (Ginhoux and Merad, 2010), possibly restricting the access of fetal liver-derived cells to the embryonic brain (Figure 1).

\section{MOVING TOWARD HARNESSING MICROGLIA TO IMPROVE HUMAN HEALTH}

It is well established that microglia are intimately involved in the pathology of neurological disease. However, efforts to elucidate the specific roles of microglia, their activation phenotypes and how they can be harnessed to ameliorate disease, are hampered by the lack of access to sufficient numbers of cells for comprehensive in vitro studies. Isolation of primary rodent microglia is generally achieved either by cell sorting or stepwise cell culture, both of which are time-consuming and generally yield few cells. While of limited use in rodents, this approach is entirely unfeasible for obtaining human microglia.

Although there has been some success producing microglialike cells from bone marrow stem cells and circulating monocytes, they are perhaps poor models of "true" microglia as these cell populations do not share the embryonic origin of the vast majority of microglia in the homeostatic brain. Furthermore, their relatively advanced states of differentiation also make them unsuitable for asking questions about the intrinsic and extrinsic regulators of microglial development and specification. In contrast, pluripotent stem cells are already widely used in investigations of embryonic development, have undergone directed differentiation into astrocytes and neuronal subtypes of the CNS, and even been used for cellular transplantation therapies for neurodegenerative diseases (Park et al., 2008a; Kiskinis and Eggan, 2010; Wu and Hochedlinger, 2011; Ben-David et al., 2012). The exciting discovery that terminally-differentiated somatic cells can be reprogrammed into an embryonic-like "induced pluripotent stem cell" (iPSC) has also opened up new possibilities for disease modeling and developing patient-specific therapies (Takahashi and Yamanaka, 2006; Okita et al., 2007; Takahashi et al., 2007; Wernig et al., 2007; Yu et al., 2007; Park et al., 2008b).

Both embryonic stem cells (ESCs) and iPSCs have virtually unlimited expansion potential, can be cultured under defined conditions to ensure reproducible and scalable differentiation protocols, and are amenable to genetic manipulation to create tools for deeper functional studies. Large-scale in vitro generation of microglia would also allow us to perform high-throughput genetic screens aiming to uncover key transcription factors responsible for specifying the microglial phenotype. Even more attractively, we could potentially differentiate iPSCs from human patients to re-create a "disease in a dish," forming a crucial bridge between animal models (which are often deficient) and pathological disease states in humans. Thus far, efforts to recapitulate neurological disease features in vitro from human iPSCs have mainly focused on the afflicted neurons (Dimos et al., 2008; Park et al., 2008b; Lee et al., 2009; Soldner et al., 2009; Marchetto et al., 2010). The development of more complex disease models incorporating multiple cell types, particularly microglia, remains a challenge.

In contrast to the numerous protocols for efficient generation of astrocytes and neurons from pluripotent stem cells (Lee et al., 2000; Zhang et al., 2001; Hu et al., 2010), there is little literature reporting methods for obtaining phenotypicallycorrect microglia from the same cell sources. An early study on the differentiation of mouse ESCs (mESCs) into CNS cells in retinoic acid-induced embryoid bodies (EBs) showed that incidental cells expressing microglial markers were generated, in addition to neurons and astrocytes (Angelov et al., 1998). This preliminary success was the motivation for subsequent attempts to generate microglia from mESCs via neuronal differentiation strategies (Tsuchiya et al., 2005; Napoli et al., 2009). In brief, mESCs were induced to differentiate as EBs following withdrawal of leukemia inhibitory factor (LIF), 
and then progenitors were expanded and further differentiated with neuronal-supportive media and cytokine stimulation. After 21-50 days CD45 $5^{\text {low }} / \mathrm{CD} 11 \mathrm{~b}^{+}$putative microglia-like cells were observed in these cultures; they expressed surface markers consistent with primary microglia, responded to classical immune activators such as lipopolysaccharide and interferon- $\gamma$, and appeared to survive implantation into the mouse brain. However, the low yields and prolonged culture period required, together with our current understanding of the ontogeny of microglia, suggest that these microglia-like cells perhaps are arising as a side population in the neuro-ectodermal differentiation process. On the other hand, we should not discount the possibility that neural cells present in these cultures might have provided a signaling milieu supportive of genuine microglial maturation. For example, brain- and bone marrowderived $\mathrm{Mac}-1^{+}$progenitors co-cultured on a supportive layer of astroglial cells proliferated and matured into microglial-like cells (Alliot et al., 1991). Sievers and colleagues also showed that co-culture with astrocytes induced blood monocytes and spleen macrophages to adopt a ramified morphology akin to microglia (Sievers et al., 1994a,b). In light of our current understanding that adult microglia originate as primitive macrophages from the embryonic YS, a more effective strategy for approaching pluripotent stem cell differentiation may be to attempt to recapitulate YS hematopoiesis in vitro (Figure 2). In the mouse, hemangioblast precursors migrate from the posterior primitive streak into the YS proper, where they form the blood islands and surrounding endothelial cells (Huber et al., 2004). YS hematopoiesis yields primitive erythroblasts as early as E7.0, followed by definitive erythroblasts and macrophage progenitors between E8.5-9.0 (Palis et al., 1999). However, it has been known for some time that these developmental stages can be closely mirrored in mESC differentiation in vitro, specifically in terms of the kinetics of hematopoietic gene expression, as well as the order in which hematopoietic progenitors appear. In two modalities of differentiation, either in a co-culture with a hematopoietic-supportive stromal cell layer such as OP9 cells, or as EBs, mESCs sequentially generate in vitro equivalents of the primitive streak, hemangioblast, and YS hematopoietic progenitors (Risau et al., 1988; Wiles and Keller, 1991; Nakano et al., 1996; Ogawa et al., 1999; Kennedy and Keller, 2003; Hirai et al., 2005). These processes in mESCs are controlled by the same molecular regulators as those operative during early hematopoiesis in vivo. For example, mouse embryos with targeted gene disruption of the hematopoietic master regulator SCL/Tal-1 have no YS hematopoiesis and fail to develop beyond E9.5 (Robb et al., 1995; Shivdasani et al., 1995); likewise abrogation of SCL expression in both mouse and human ESCs

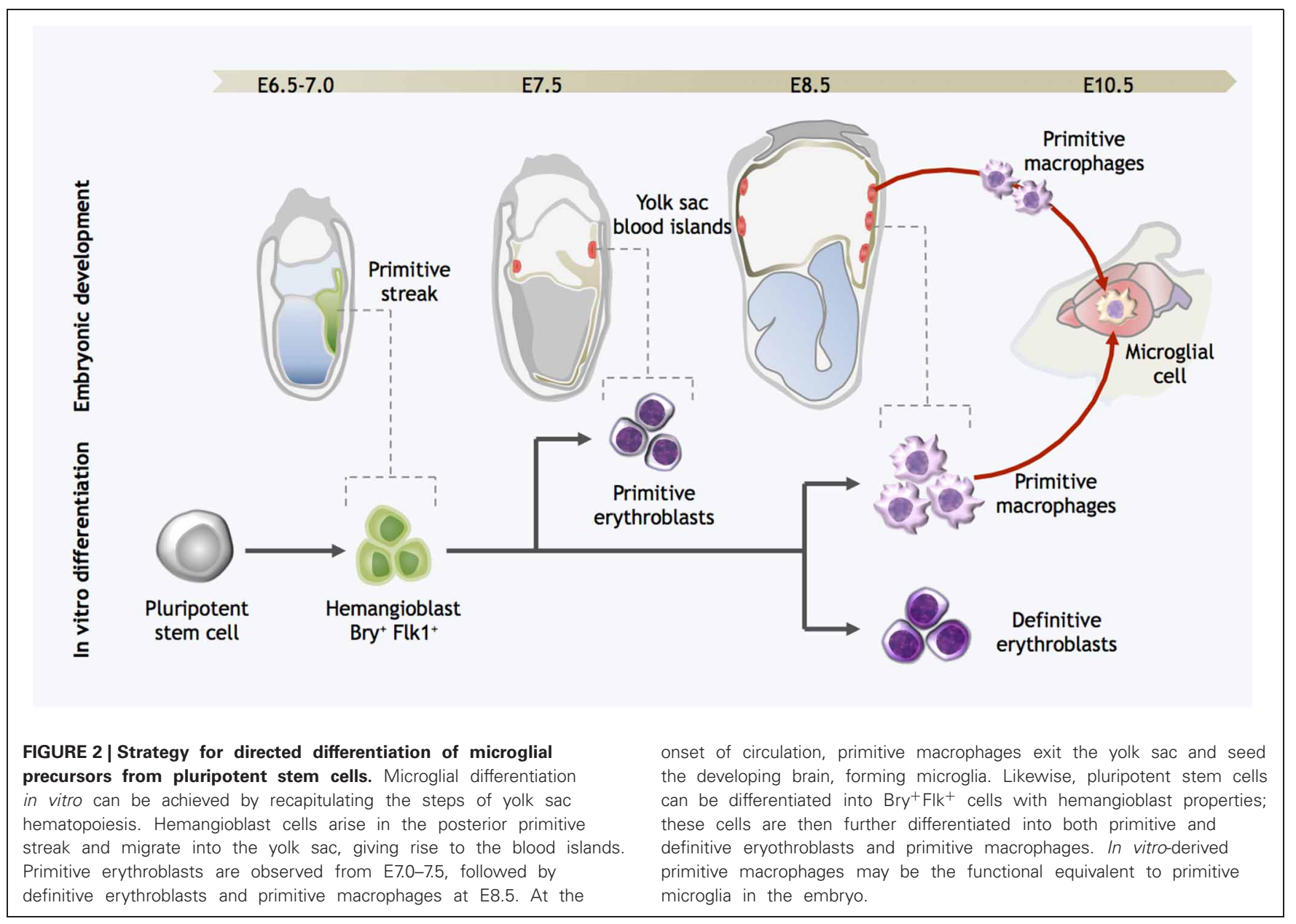


completely represses early hematopoietic specification (D'souza et al., 2005; Real et al., 2012). Similarly, PU.1 KO ESCs could not be differentiated into macrophages (Henkel et al., 1996; Anderson et al., 1998), consistent with the finding that PU.1 KO embryos lack both macrophages and microglia (McKercher et al., 1996).

However, useful the mouse developmental model may be, the paucity of equivalent human in vivo models makes it imperative to develop accurate in vitro alternatives using human pluripotent stem cells. Classical lineage tracing studies of blood development in human embryos showed that many essential features of YS hematopoiesis are conserved from mice to humans (Migliaccio et al., 1986; Huyhn et al., 1995; Palis and Yoder, 2001). As was the case in the mouse system, human pluripotent stem cells could also be differentiated into cells representative of the early hematopoietic developmental stages, albeit with extended kinetics (Wang et al., 2004; Zambidis et al., 2005; Kennedy et al., 2007), suggesting that hematopoietic cell emergence in the YS might be closely modeled by human ESC differentiation (Zambidis et al., 2005).

Given their direct ontogenetic relationship, we postulate that techniques for directing primitive macrophage fate specification from pluripotent stem cells will also yield microglial precursors. Our proposed approach is to further refine protocols for recapitulating YS hematopoiesis, with the aim of increasing the yield of primitive macrophages and levels of reproducibility. Serum-based protocols introduce intrinsic variability, so we will turn to a defined serum-free and feeder cellfree procedure, using only specific combinations of cytokines to replicate the developmental signals during embryogenesis. The key challenge in this approach will be to screen appropriate combinations of factors as well as the time window for treatment. Candidate primitive macrophage/microglial cells can then be isolated based on surface marker expression, and assayed for microglial-appropriate phenotypes such as response to immune stimulation, morphological analysis and phagocytic ability (Giulian and Baker, 1986; Sedgwick et al., 1991). Eventually, the ability to engraft within the brain, with classic resting microglial morphology will be the true test of successful differentiation.

\section{CONCLUSION}

The "origin of murine microglia controversy" is now resolved in steady state conditions and in a few mouse models of CNS pathologies. We have learned that microglia arise from YS macrophages that seed the brain rudiment from the cephalic mesenchyme very early during development, as predicted earlier by the founder of the microglia field, Pio del Rio-Hortega. Importantly, embryonically-derived microglia will maintain themselves until adulthood. While much progress has been made in terms of our understanding of both the origin and importance of microglia, many questions remain unanswered.

As discussed before, this knowledge may have implications for the use of embryonically-derived microglial progenitors in the treatment of brain inflammatory diseases. Moreover, these results have fundamental implications for the understanding of microglial function in CNS development. First, the conservation of primitive macrophages and their YS derivation throughout evolution and across diverse species suggests that microglia play an important physiological role in the development of the CNS. Furthermore, microglial cells are present in all stages of brain development, including the early prenatal stages of neuronal circuit building as well as the post-natal stage of synapse elimination.

An earlier report had highlighted that, in contrast to their broad distribution in the adult brain, embryonic microglia have a strikingly uneven distribution during embryogenesis (Perry et al., 1985). Microglial cells accumulate in hot spots that were initially proposed to be most likely related to the clearance of apoptotic bodies and the remodeling of brain tissues. In light of the recent work which has shown that microglia contribute to the control of synaptic connections, it will be interesting to verify whether such hotspots co-localize with areas crucial for neuronal development. This will indicate that microglia play an important role in development of neuronal circuits of the brain and proposes more questions to be answered regarding the integrated development of the neural and immune systems. Such questions also have tremendous implications beyond the simple biology of microglia. Do defects affecting microglial development have a long-term impact on the functional vulnerability of CNS? And do defects in microglial function perhaps contribute to synaptic abnormalities seen in some neurodevelopmental disorders? In support of such hypotheses, prenatal inflammation, which triggers the activation of microglia, is thought to be a risk factor for the development of neuropsychiatric disorders such as schizophrenia and autism spectrum disorders in the unborn child (Patterson, 2009, 2011).

Importantly, embryonic microglia will maintain themselves until adulthood via local proliferation during late gestation and post-natal development as well as in the injured adult brain in reaction to inflammation. They are unlikely to be replaced by blood-derived monocytes or any bone marrow-derived cells. Nevertheless, during certain inflammatory conditions found for example after bone marrow transplantation or in chronic neurodegenerative diseases such as Multiple Sclerosis and Alzheimer's disease (Simard and Rivest, 2006; Jung and Schwartz, 2012), the recruitment of monocytes or other bone marrow-derived progenitors can supplement the microglial population to some extent, but we do not understand whether these cells persist and become integrated, or are a temporary addition to the endogenous population. The interactive dynamic between embryonic and adult microglial populations requires further study: We need now to understand to what extent the endogenous microglia is replaced, where and how it is done, and if engrafted cells have a selective advantage over the endogenous microglia, how well they "compete" against the endogenous embryonic microglial population and how long they will persist. Finally, we do not know yet precisely if these bone marrow-derived microglia can fulfill the functional roles of the endogenous population.

\section{ACKNOWLEDGMENTS}

This work was supported by the Singapore Immunology Network core grant. We thank Dr. L. Robinson for critical review and editing of the manuscript. 


\section{REFERENCES}

Ajami, B., Bennett, J. L., Krieger, C., McNagny, K. M., and Rossi, F. M. (2011). Infiltrating monocytes trigger EAE progression, but do not contribute to the resident microglia pool. Nat. Neurosci. 14, 1142-1149.

Ajami, B., Bennett, J. L., Krieger, C., Tetzlaff, W., and Rossi, F. M. (2007). Local self-renewal can sustain CNS microglia maintenance and function throughout adult life. Nat. Neurosci. 10, 1538-1543.

Akiyama, H., and McGeer, P. L. (1990). Brain microglia constitutively express beta-2 integrins. J. Neuroimmunol. 30, 81-93.

Alliot, F., Godin, I., and Pessac, B. (1999). Microglia derive from progenitors, originating from the yolk sac, and which proliferate in the brain. Brain Res. Dev. Brain Res. 117, 145-152.

Alliot, F., Lecain, E., Grima, B., and Pessac, B. (1991). Microglial progenitors with a high proliferative potential in the embryonic and adult mouse brain. Proc. Natl. Acad. Sci. U.S.A. 88, 1541-1545.

Anderson, K. L., Smith, K. A., Conners, K., McKercher, S. R., Maki, R. A., and Torbett, B. E. (1998). Myeloid development is selectively disrupted in PU.1 null mice. Blood 91, 3702-3710.

Angelov, D. N., Arnhold, S., Andressen, C., Grabsch, H., Puschmann, M., Hescheler, J., et al. (1998). Temporospatial relationships between macroglia and microglia during in vitro differentiation of murine stem cells. Dev. Neurosci. 20, 42-51.

Ashwell, K. (1990). Microglia and cell death in the developing mouse cerebellum. Brain Res. Dev. Brain Res. $55,219-230$

Ashwell, K. W., and Waite, P. M. (1991). Cell death in the developing trigeminal nuclear complex of the rat. Brain Res. Dev. Brain Res. 63, 291-295.

Baron, M., and Gallego, A. (1972). The relation of the microglia with the pericytes in the cat cerebral cortex. Z. Zellforsch. Mikrosk. Anat. 128, 42-57.

Beers, D. R., Henkel, J. S., Xiao, Q., Zhao, W., Wang, J., Yen, A. A., et al. (2006). Wild-type microglia extend survival in PU.1 knockout mice with familial amyotrophic lateral sclerosis. Proc. Natl. Acad. Sci. U.S.A. 103, 16021-16026.

Ben-David, U., Kopper, O., and Benvenisty, N. (2012). Expanding the boundaries of embryonic stem cells. Cell Stem Cell 10, 666-677.
Bertrand, J. Y., Jalil, A., Klaine, M., Jung, S., Cumano, A., and Godin, I. (2005). Three pathways to mature macrophages in the early mouse yolk sac. Blood 106, 3004-3011.

Biffi, A., De Palma, M., Quattrini, A., Del Carro, U., Amadio, S., Visigalli, I., et al. (2004). Correction of metachromatic leukodystrophy in the mouse model by transplantation of genetically modified hematopoietic stem cells. J. Clin. Invest. 113, 1118-1129.

Capotondo, A., Milazzo, R., Politi, L. S., Quattrini, A., Palini, A., Plati, T., et al. (2012). Brain conditioning is instrumental for successful microglia reconstitution following hematopoietic stem cell transplantation. Proc. Natl. Acad. Sci. U.S.A. 109, 15018-15023.

Chan, W. Y., Kohsaka, S., and Rezaie, P. (2007). The origin and cell lineage of microglia: new concepts. Brain Res. Rev. 53, 344-354.

Chen, S. K., Tvrdik, P., Peden, E., Cho, S., Wu, S., Spangrude, G., et al. (2010). Hematopoietic origin of pathological grooming in Hoxb8 mutant mice. Cell 141, 775-785.

Cuadros, M. A., and Navascues, J. (1998). The origin and differentiation of microglial cells during development. Prog. Neurobiol. 56, 173-189.

D'souza, S. L., Elefanty, A. G., and Keller, G. (2005). SCL/Tal-1 is essential for hematopoietic commitment of the hemangioblast but not for its development. Blood 105, 3862-3870.

Daneman, R. (2012). The blood-brain barrier in health and disease. Ann. Neurol. 72, 648-672.

Daneman, R., Zhou, L., Kebede, A. A., and Barres, B. A. (2010). Pericytes are required for blood-brain barrier integrity during embryogenesis. Nature 468, 562-566.

De Groot, C. J., Huppes, W., Sminia T., Kraal, G., and Dijkstra, C. D. (1992). Determination of the origin and nature of brain macrophages and microglial cells in mouse central nervous system, using nonradioactive in situ hybridization and immunoperoxidase techniques. Glia 6, 301-309.

Derecki, N. C., Cronk, J. C., Lu, Z., Xu, E., Abbott, S. B., Guyenet, P. G., et al. (2012). Wild-type microglia arrest pathology in a mouse model of Rett syndrome. Nature 484, 105-109.

Dimos, J. T., Rodolfa, K. T., Niakan, K. K., Weisenthal, L. M., Mitsumoto, H., Chung, W., et al. (2008). Induced pluripotent stem cells generated from patients with ALS can be differentiated into motor neurons. Science 321, 1218-1221.

Diserbo, M., Agin, A., Lamproglou, I., Mauris, J., Staali, F., Multon, E., et al. (2002). Blood-brain barrier permeability after gamma whole-body irradiation: an in vivo microdialysis study. Can. J. Physiol. Pharmacol. 80 670-678.

Eglitis, M. A., and Mezey, E. (1997) Hematopoietic cells differentiate into both microglia and macroglia in the brains of adult mice. Proc. Natl. Acad. Sci. U.S.A. 94 4080-4085.

Esiri, M. M., Al Izzi, M. S., and Reading, M. C. (1991). Macrophages, microglial cells, and HLA-DR antigens in fetal and infant brain. J. Clin. Pathol. 44, 102-106.

Fedoroff, S., Zhai, R., and Novak, J. P. (1997). Microglia and astroglia have a common progenitor cell. J. Neurosci. Res. 50, 477-486.

Fujita, S., and Kitamura, T. (1975). Origin of brain macrophages and the nature of the so-called microglia. Acta Neuropathol. Suppl. 6, 291-296.

Ginhoux, F., Greter, M., Leboeuf, M., Nandi, S., See, P., Gokhan, S., et al. (2010). Fate mapping analysis reveals that adult microglia derive from primitive macrophages. Science 330, 841-845.

Ginhoux, F., and Merad, M. (2010). Ontogeny and homeostasis of Langerhans cells. Immunol. Cell Biol. 88, 387-392.

Giulian, D., and Baker, T. J. (1986) Characterization of ameboid microglia isolated from developing mammalian brain. J. Neurosci. 6 , 2163-2178.

Godin, I. E., Garcia-Porrero, J. A., Coutinho, A., Dieterlen-Lievre, F. and Marcos, M. A. (1993). Paraaortic splanchnopleura from early mouse embryos contains Bla cell progenitors. Nature 364, 67-70

Graeber, M. B. (2010). Changing face of microglia. Science 330, 783-788.

Hao, C., Richardson, A., and Fedoroff, S. (1991). Macrophage-like cells originate from neuroepithelium in culture: characterization and properties of the macrophagelike cells. Int. J. Dev. Neurosci. 9, 1-14.

Henkel, G. W., McKercher, S. R., Yamamoto, H., Anderson, K. L., Oshima, R. G., and Maki, R. A (1996). PU.1 but not ets-2 is essential for macrophage development from embryonic stem cells. Blood 88, 2917-2926.

Herbomel, P., Thisse, B., and Thisse, C. (1999). Ontogeny and behaviour of early macrophages in the zebrafish embryo. Development 126, 3735-3745.

Herbomel, P., Thisse, B., and Thisse, C. (2001). Zebrafish early macrophages colonize cephalic mesenchyme and developing brain, retina, and epidermis through a M-CSF receptor-dependent invasive process. Dev. Biol. 238, 274-288.

Hickey, W. F., and Kimura, H. (1988). Perivascular microglial cells of the CNS are bone marrow-derived and present antigen in vivo. Science 239, 290-292.

Hirai, H., Samokhvalov, I. M., Fujimoto, T., Nishikawa, S., and Imanishi, J. (2005). Involvement of Runx1 in the down-regulation of fetal liver kinase-1 expression during transition of endothelial cells to hematopoietic cells. Blood 106, 1948-1955.

Hoeffel, G., Wang, Y., Greter, M., See, P., Teo, P., Malleret, B., et al. (2012). Adult Langerhans cells derive predominantly from embryonic fetal liver monocytes with a minor contribution of yolk sac-derived macrophages. J. Exp. Med. 209, 1167-1181.

Hu, B. Y., Weick, J. P., Yu, J., Ma, L. X., Zhang, X. Q., Thomson, J. A., et al. (2010). Neural differentiation of human induced pluripotent stem cells follows developmental principles but with variable potency. Proc. Natl. Acad. Sci. U.S.A. 107, 4335-4340.

Huber, T. L., Kouskoff, V., Fehling, H. J., Palis, J., and Keller, G. (2004). Haemangioblast commitment is initiated in the primitive streak of the mouse embryo. Nature 432, 625-630.

Hughes, V. (2012). Microglia: the constant gardeners. Nature 485, 570-572.

Hume, D. A., Perry, V. H., and Gordon, S. (1983). Immunohistochemical localization of a macrophagespecific antigen in developing mouse retina: phagocytosis of dying neurons and differentiation of microglial cells to form a regular array in the plexiform layers. J. Cell Biol. 97, 253-257.

Hutchins, K. D., Dickson, D. W. Rashbaum, W. K., and Lyman, W. D. (1990). Localization of morphologically distinct microglial populations in the developing human fetal brain: implications for ontogeny. Brain Res. Dev. Brain Res. 55, 95-102.

Huyhn, A., Dommergues, M., Izac, B., Croisille, L., Katz, A., Vainchenker, W., et al. (1995). Characterization of hematopoietic progenitors from human yolk sacs and embryos. Blood 86, 4474-4485. 
Imamoto, K., and Leblond, C. P. (1978). Radioautographic investigation of gliogenesis in the corpus callosum of young rats. II. Origin of microglial cells. J. Comp. Neurol. 180, 139-163.

Janossy, G., Bofill, M., Poulter, L. W., Rawlings, E., Burford, G. D., Navarrete, C., et al. (1986). Separate ontogeny of two macrophage-like accessory cell populations in the human fetus. J. Immunol. 136, 4354-4361.

Jung, S., and Schwartz, M. (2012). Non-identical twins microglia and monocyte-derived macrophages in acute injury and autoimmune inflammation. Front. Immunol. 3:89. doi: 10.3389/fimmu.2012.00089

Kennedy, M., D'souza, S. L., LynchKattman, M., Schwantz, S., and Keller, G. (2007). Development of the hemangioblast defines the onset of hematopoiesis in human ES cell differentiation cultures. Blood 109, 2679-2687.

Kennedy, M., and Keller, G. M. (2003). Hematopoietic commitment of ES cells in culture. Meth. Enzymol. 365, 39-59.

Kettenmann, H., Hanisch, U. K., Noda, M., and Verkhratsky, A. (2011). Physiology of microglia. Physiol. Rev. 91, 461-553.

Kierdorf, K., Erny, D., Goldmann, T., Sander, V., Schulz, C., Perdiguero, E. G., et al. (2013). Microglia emerge from erythromyeloid precursors via Pu.1- and Irf8-dependent pathways. Nat. Neurosci. 16, 273-280.

Kingwell, K. (2012). Neurodegenerative disease: microglia in early disease stages. Nat. Rev. Neurol. 8, 475.

Kiskinis, E., and Eggan, K. (2010). Progress toward the clinical application of patient-specific pluripotent stem cells. J. Clin. Invest. 120, 51-59.

Kitamura, T., Miyake, T., and Fujita, S. (1984). Genesis of resting microglia in the gray matter of mouse hippocampus. J. Comp. Neurol. 226, 421-433.

Koushik, S. V., Wang, J., Rogers, R., Moskophidis, D., Lambert, N. A., Creazzo, T. L., et al. (2001). Targeted inactivation of the sodium-calcium exchanger (Ncxl) results in the lack of a heartbeat and abnormal myofibrillar organization. FASEB J. 15, 1209-1211.

Kumaravelu, P., Hook, L., Morrison, A. M., Ure, J., Zhao, S., Zuyev, S., et al. (2002). Quantitative developmental anatomy of definitive haematopoietic stem cells/long-term repopulating units (HSC/RUs): role of the aortagonad-mesonephros (AGM) region and the yolk sac in colonisation of the mouse embryonic liver. Development 129, 4891-4899.

Kurz, H., Korn, J., Eggli, P. S., Huang, R., and Christ, B. (2001). Embryonic central nervous system angiogenesis does not involve blood-borne endothelial progenitors. J. Comp. Neurol. 436, 263-274.

Ladeby, R., Wirenfeldt, M., GarciaOvejero, D., Fenger, C., DissingOlesen, L., Dalmau, I., et al. (2005). Microglial cell population dynamics in the injured adult central nervous system. Brain Res. Brain Res. Rev. 48 196-206.

Lassmann, H., Schmied, M., Vass, K., and Hickey, W. F. (1993). Bone marrow derived elements and resident microglia in brain inflammation. Glia 7, 19-24.

Lawson, L. J., Perry, V. H., Dri, P., and Gordon, S. (1990). Heterogeneity in the distribution and morphology of microglia in the normal adult mouse brain. Neuroscience 39, 151-170.

Lawson, L. J., Perry, V. H., and Gordon, S. (1992). Turnover of resident microglia in the normal adult mouse brain. Neuroscience 48 , 405-415.

Lee, G., Papapetrou, E. P., Kim, H. Chambers, S. M., Tomishima, M. J., Fasano, C. A., et al. (2009). Modelling pathogenesis and treatment of familial dysautonomia using patient-specific iPSCs. Nature 461, 402-406.

Lee, S. H., Lumelsky, N., Studer, L., Auerbach, J. M., and McKay, R. D. (2000). Efficient generation of midbrain and hindbrain neurons from mouse embryonic stem cells. Nat. Biotechnol. 18, 675-679.

Leong, S. K., and Ling, E. A. (1992). Amoeboid and ramified microglia: their interrelationship and response to brain injury. Glia 6, 39-47.

Lewis, P. D. (1968). The fate of the subependymal cell in the adult rat brain, with a note on the origin of microglia. Brain 91, 721-736.

Li, Y. Q., Chen, P., Jain, V., Reilly, R. M., and Wong, C. S. (2004). Early radiation-induced endothelial cell loss and blood-spinal cord barrier breakdown in the rat spinal cord. Radiat. Res. 161, 143-152.

Lichanska, A. M., and Hume, D. A. (2000). Origins and functions of phagocytes in the embryo. Exp. Hematol. 28, 601-611.

Linard, C., Marquette, C., Mathieu, J., Pennequin, A., Clarencon, D., and Mathe, D. (2004). Acute induction of inflammatory cytokine expression after gamma-irradiation in the rat: effect of an NF-kappaB inhibitor. Int. J. Radiat. Oncol. Biol. Phys. 58, 427-434.

Ling, E. A. (1976). Some aspects of amoeboid microglia in the corpus callosum and neighbouring regions of neonatal rats. J. Anat. 121, 29-45.

Ling, E. A. (1979). Transformation of monocytes into amoeboid microglia in the corpus callosum of postnatal rats, as shown by labelling monocytes by carbon particles. J. Anat. $128,847-858$.

Ling, E. A., Penney, D., and Leblond, C. P. (1980). Use of carbon labeling to demonstrate the role of blood monocytes as precursors of the 'ameboid cells' present in the corpus callosum of postnatal rats. J. Comp. Neurol. 193, 631-657.

Marchetto, M. C., Carromeu, C., Acab, A., Yu, D., Yeo, G. W., Mu, Y., et al. (2010). A model for neural development and treatment of Rett syndrome using human induced pluripotent stem cells. Cell 143, 527-539.

Matsumoto, Y., and Fujiwara, M (1987). Absence of donor-type major histocompatibility complex class I antigen-bearing microglia in the rat central nervous system of radiation bone marrow chimeras. J. Neuroimmunol. 17, 71-82.

McGrath, K. E., Koniski, A. D., Malik, J., and Palis, J. (2003). Circulation is established in a stepwise pattern in the mammalian embryo. Blood 101, 1669-1676.

McKercher, S. R., Torbett, B. E., Anderson, K. L., Henkel, G. W. Vestal, D. J., Baribault, H., et al. (1996). Targeted disruption of the PU.1 gene results in multiple hematopoietic abnormalities. EMBO J. 15, 5647-5658.

Medvinsky, A. L., Samoylina, N. L. Muller, A. M., and Dzierzak, E. A. (1993). An early pre-liver intraembryonic source of CFU-S in the developing mouse. Nature 364, 64-67.

Mezey, E., Chandross, K. J., Harta, G., Maki, R. A., and McKercher, S. R. (2000). Turning blood into brain: cells bearing neuronal antigens generated in vivo from bone marrow. Science 290, 1779-1782.

Migliaccio, G., Migliaccio, A. R., Petti S., Mavilio, F., Russo, G., Lazzaro, D., et al. (1986). Human embryonic hemopoiesis. Kinetics of progenitors and precursors underlying the yolk sac-liver transition. J. Clin Invest. 78, 51-60.

Mildner, A., Schlevogt, B., Kierdorf, K., Bottcher, C., Erny, D., Kummer, M. P., et al. (2011). Distinct and nonredundant roles of microglia and myeloid subsets in mouse models of Alzheimer's disease. J. Neurosci. 31, 11159-11171.

Mildner, A., Schmidt, H., Nitsche, M., Merkler, D., Hanisch, U. K. Mack, M., et al. (2007). Microglia in the adult brain arise from Ly-6ChiCCR2+ monocytes only under defined host conditions. Nat. Neurosci. 10, 1544-1553.

Mizutani, M., Pino, P. A., Saederup, N., Charo, I. F., Ransohoff, R M., and Cardona, A. E. (2012). The fractalkine receptor but not CCR2 is present on microglia from embryonic development throughout adulthood. J. Immunol. 188, 29-36.

Monier, A., Adle-Biassette, H., Delezoide, A. L., Evrard, P., Gressens, P., and Verney, C. (2007). Entry and distribution of microglial cells in human embryonic and fetal cerebral cortex. J. Neuropathol. Exp. Neurol. 66, 372-382.

Moore, M. A., and Metcalf, D. (1970). Ontogeny of the haemopoietic system: yolk sac origin of in vivo and in vitro colony forming cells in the developing mouse embryo. Br. J. Haematol. 18 279-296.

Mori, S., and Leblond, C. P. (1969). Identification of microglia in light and electron microscopy. J. Comp. Neurol. 135, 57-80.

Morris, L., Graham, C. F., and Gordon, S. (1991). Macrophages in haemopoietic and other tissues of the developing mouse detected by the monoclonal antibody F4/80. Development 112, 517-526.

Murabe, Y., and Sano, Y. (1982). Morphological studies on neuroglia. VI. Postnatal development of microglial cells. Cell Tissue Res. 225, 469-485.

Murabe, Y., and Sano, Y. (1983). Morphological studies on neuroglia. VII. Distribution of "brain macrophages" in brains of neonatal and adult rats, as determined by means of immunohistochemistry. Cell Tissue Res. 229, 85-95.

Naito, M., Takahashi, K., and Nishikawa, S. (1990). Development, differentiation, and maturation of macrophages in the fetal mouse liver. J. Leukoc. Biol. 48, 27-37.

Naito, M., Umeda, S., Yamamoto T., Moriyama, H., Umezu, H., Hasegawa, G., et al. (1996). Development, differentiation, and phenotypic heterogeneity of murine tissue macrophages. J. Leukoc. Biol. 59, 133-138.

Nakano, T., Kodama, H., and Honjo, T. (1996). In vitro development of primitive and definitive 
erythrocytes from different precursors. Science 272, 722-724.

Napoli, I., Kierdorf, K., and Neumann, H. (2009). Microglial precursors derived from mouse embryonic stem cells. Glia 57, 1660-1671.

North, T., Gu, T. L., Stacy, T., Wang, Q., Howard, L., Binder, M., et al. (1999). $\mathrm{Cbfa} 2$ is required for the formation of intra-aortic hematopoietic clusters. Development 126, 2563-2575.

Oehmichen, M., Wietholter, H., Gruninger, H., and Gencic, M. (1979). Features and distribution of intracerebrally injected peritoneal macrophages. Exp. Pathol. (Jena) 17, 71-76.

Ogawa, M., Kizumoto, M., Nishikawa, S., Fujimoto, T., Kodama, H., and Nishikawa, S. I. (1999). Expression of alpha4-integrin defines the earliest precursor of hematopoietic cell lineage diverged from endothelial cells. Blood 93, 1168-1177.

Okita, K., Ichisaka, T., and Yamanaka, S. (2007). Generation of germlinecompetent induced pluripotent stem cells. Nature 448, 313-317.

Orkin, S. H., and Zon, L. I. (2008). Hematopoiesis: an evolving paradigm for stem cell biology. Cell 132, 631-644.

Palis, J., Robertson, S., Kennedy, M., Wall, C., and Keller, G. (1999). Development of erythroid and myeloid progenitors in the yolk sac and embryo proper of the mouse. Development 126, 5073-5084.

Palis, J., and Yoder, M. C. (2001). Yolk-sac hematopoiesis: the first blood cells of mouse and man. Exp. Hematol. 29, 927-936.

Paolicelli, R. C., Bolasco, G., Pagani, F., Maggi, L., Scianni, M., Panzanelli, P., et al. (2011). Synaptic pruning by microglia is necessary for normal brain development. Science 333, 1456-1458.

Park, I. H., Arora, N., Huo, H., Maherali, N., Ahfeldt, T., Shimamura, A., et al. (2008a). Disease-specific induced pluripotent stem cells. Cell 134, 877-886.

Park, I. H., Zhao, R., West, J. A., Yabuuchi, A., Huo, H., Ince, T. A., et al. (2008b). Reprogramming of human somatic cells to pluripotency with defined factors. Nature 451, 141-146.

Patterson, P. H. (2009). Immune involvement in schizophrenia and autism: etiology, pathology and animal models. Behav. Brain Res. 204, 313-321.

Patterson, P. H. (2011). Maternal infection and immune involvement in autism. Trends Mol. Med. 17, 389-394.
Perry, V. H. (1998). A revised view of the central nervous system microenvironment and major histocompatibility complex class II antigen presentation. J. Neuroimmunol. 90 113-121.

Perry, V. H., Hume, D. A., and Gordon, S. (1985). Immunohistochemical localization of macrophages and microglia in the adult and developing mouse brain. Neuroscience 15, 313-326.

Perry, V. H., Nicoll, J. A., and Holmes, C. (2010). Microglia in neurodegenerative disease. Nat. Rev. Neurol. 6, 193-201.

Priller, J., Flugel, A., Wehner, T., Boentert, M., Haas, C. A., Prinz, M., et al. (2001). Targeting genemodified hematopoietic cells to the central nervous system: use of green fluorescent protein uncovers microglial engraftment. Nat. Med. 7 , 1356-1361.

Real, P. J., Ligero, G., Ayllon, V., RamosMejia, V., Bueno, C., GutierrezAranda, I., et al. (2012). SCL/TAL1 regulates hematopoietic specification from human embryonic stem cells. Mol. Ther. 20, 1443-1453.

Rezaie, P. (2003). Microglia in the human nervous system during development. Neuroembryology 2, 18-31.

Rezaie, P., Dean, A., Male, D., and Ulfig, N. (2005). Microglia in the cerebral wall of the human telencephalon at second trimester. Cereb. Cortex 15, 938-949.

Rezaie, P., and Male, D. (1999). Colonisation of the developing human brain and spinal cord by microglia: a review. Microsc. Res. Tech. 45, 359-382.

Rezaie, P., and Male, D. (2002). Mesoglia and microglia-a historical review of the concept of mononuclear phagocytes within the central nervous system. J. Hist. Neurosci. $11,325-374$.

Rio-Hortega, D. (1932). "Microglia," in Cytology and Cellular Pathology of the Nervous System, Vol. 2, ed W. Penfield, (New York, NY: P. B. Hoeber, Inc.), 482-534.

Rio-Hortega, D. (1939). The Microglia. Lancet 233, 1023-1026.

Risau, W., Sariola, H., Zerwes, H. G., Sasse, J., Ekblom, P., Kemler, R., et al. (1988). Vasculogenesis and angiogenesis in embryonicstem-cell-derived embryoid bodies. Development 102, 471-478.

Robb, L., Lyons, I., Li, R., Hartley, L., Kontgen, F., Harvey, R. P., et al. (1995). Absence of yolk sac hematopoiesis from mice with a targeted disruption of the scl gene.
Proc. Natl. Acad. Sci. U.S.A. 92, 7075-7079.

Samokhvalov, I. M., Samokhvalova, N I., and Nishikawa, S. (2007). Cell tracing shows the contribution of the yolk sac to adult haematopoiesis. Nature 446, 1056-1061.

Schelper, R. L., and Adrian, E. K. Jr. (1986). Monocytes become macrophages; they do not become microglia: a light and electron microscopic autoradiographic study using 125-iododeoxyuridine. J. Neuropathol. Exp. Neurol. 45, 1-19.

Schulz, C., Gomez Perdiguero, E. Chorro, L., Szabo-Rogers, H., Cagnard, N., Kierdorf, K., et al. (2012). A lineage of myeloid cells independent of $\mathrm{Myb}$ and hematopoietic stem cells. Science 336, 86-90.

Sedgwick, J. D., Schwender, S., Imrich, H., Dorries, R., Butcher, G. W., and Ter Meulen, V. (1991). Isolation and direct characterization of resident microglial cells from the normal and inflamed central nervous system. Proc. Natl. Acad. Sci. U.S.A. 88, 7438-7442.

Shivdasani, R. A., Mayer, E. L., and Orkin, S. H. (1995). Absence of blood formation in mice lacking the T-cell leukaemia oncoprotein tal1/SCL. Nature 373, 432-434.

Sievers, J., Parwaresch, R., and Wottge, H. U. (1994a). Blood monocytes and spleen macrophages differentiate into microglia-like cells on monolayers of astrocytes: morphology. Glia 12, 245-258.

Sievers, J., Schmidtmayer, J., and Parwaresch, R. (1994b). Blood monocytes and spleen macrophages differentiate into microglia-like cells when cultured on astrocytes. Ann Anat. 176, 45-51.

Simard, A. R., and Rivest, S. (2004) Bone marrow stem cells have the ability to populate the entire central nervous system into fully differentiated parenchymal microglia. FASEB J. 18, 998-1000.

Simard, A. R., and Rivest, S. (2006) Neuroprotective properties of the innate immune system and bone marrow stem cells in Alzheimer's disease. Mol. Psychiatry $11,327-335$.

Soldner, F., Hockemeyer, D., Beard, C., Gao, Q., Bell, G. W., Cook, E. G., et al. (2009). Parkinson's disease patient-derived induced pluripotent stem cells free of viral reprogramming factors. Cell 136, 964-977.

Sorokin, S. P., Hoyt, R. F. Jr., Blunt, D. G., and McNelly, N. A. (1992). Macrophage development: II. Early ontogeny of macrophage populations in brain, liver, and lungs of rat embryos as revealed by a lectin marker. Anat. Rec. 232, 527-550.

Takahashi, K., and Naito, M. (1993). Development, differentiation, and proliferation of macrophages in the rat yolk sac. Tissue Cell 25, 351-362.

Takahashi, K., Tanabe, K., Ohnuki, M., Narita, M., Ichisaka, T., Tomoda, K., et al. (2007). Induction of pluripotent stem cells from adult human fibroblasts by defined factors. Cell $131,861-872$.

Takahashi, K., Yamamura, F., and Naito, M. (1989). Differentiation, maturation, and proliferation of macrophages in the mouse yolk sac: a light-microscopic, enzyme-cytochemical, immunohistochemical, and ultrastructural study. J. Leukoc. Biol. 45, 87-96.

Takahashi, K., and Yamanaka, S. (2006). Induction of pluripotent stem cells from mouse embryonic and adult fibroblast cultures by defined factors. Cell 126, 663-676.

Tambuyzer, B. R., Ponsaerts, P., and Nouwen, E. J. (2009). Microglia: gatekeepers of central nervous system immunology. J. Leukoc. Biol. 85 , 352-370.

Tavian, M., and Peault, B. (2005). Embryonic development of the human hematopoietic system. Int. J. Dev. Biol. 49, 243-250.

Tremblay, M. E., Lowery, R. L., and Majewska, A. K. (2010). Microglial interactions with synapses are modulated by visual experience. PLoS Biol. 8:e1000527. doi: 10.1371/journal.pbio. 1000527

Tsuchiya, T., Park, K. C., Toyonaga, S., Yamada, S. M., Nakabayashi, H., Nakai, E., et al. (2005). Characterization of microglia induced from mouse embryonic stem cells and their migration into the brain parenchyma. J. Neuroimmunol. 160, 210-218.

Unger, E. R., Sung, J. H., Manivel, J. C., Chenggis, M. L., Blazar, B. R., and Krivit, W. (1993). Male donor-derived cells in the brains of female sex-mismatched bone marrow transplant recipients: a Y-chromosome specific in situ hybridization study. J. Neuropathol. Exp. Neurol. 52, 460-470.

Vallieres, L., and Sawchenko, P. E. (2003). Bone marrow-derived cells that populate the adult mouse brain preserve their hematopoietic identity. J. Neurosci. 23, 5197-5207.

Varvel, N. H., Grathwohl, S. A., Baumann, F., Liebig, C., Bosch, A., Brawek, B., et al. (2012). Microglial repopulation model reveals a robust homeostatic process for replacing 
CNS myeloid cells. Proc. Natl. Acad. Sci. U.S.A. 109, 18150-18155.

Verney, C., Monier, A., Fallet-Bianco, C., and Gressens, P. (2010). Early microglial colonization of the human forebrain and possible involvement in periventricular white-matter injury of preterm infants. J. Anat. 217, 436-448.

Wang, C. C., Wu, C. H., Shieh, J. Y., Wen, C. Y., and Ling, E. A. (1996). Immunohistochemical study of amoeboid microglial cells in fetal rat brain. J. Anat. 189(Pt 3), 567-574.

Wang, L., Li, L., Shojaei, F., Levac, K., Cerdan, C., Menendez, P., et al. (2004). Endothelial and hematopoietic cell fate of human embryonic stem cells originates from primitive endothelium with hemangioblastic properties. Immunity 21, 31-41.

Wernig, M., Meissner, A., Foreman, R., Brambrink, T., $\mathrm{Ku}, \quad \mathrm{M}$.,
Hochedlinger, K., et al. (2007). In vitro reprogramming of fibroblasts into a pluripotent ES-cell-like state. Nature 448 318-324.

Wiles, M. V., and Keller, G. (1991) Multiple hematopoietic lineages develop from embryonic stem (ES) cells in culture. Development 111, 259-267.

Wood, G. W., Gollahon, K. A., Tilzer, S. A., Vats, T., and Morantz, R. A. (1979). The failure of microglia in normal brain to exhibit mononuclear phagocyte markers. J. Neuropathol. Exp. Neurol. 38, 369-376.

Wu, S. M., and Hochedlinger, K. (2011). Harnessing the potential of induced pluripotent stem cells for regenerative medicine. Nat. Cell Biol. 13, 497-505.

Yu, J., Vodyanik, M. A., Smuga-Otto, K., Antosiewicz-Bourget, J., Frane, J.
L., Tian, S., et al. (2007). Induced pluripotent stem cell lines derived from human somatic cells. Science 318, 1917-1920.

Zambidis, E. T., Peault, B., Park, T. S., Bunz, F., and Civin, C. I. (2005). Hematopoietic differentiation of human embryonic stem cells progresses through sequential hematoendothelial, primitive, and definitive stages resembling human yolk sac development. Blood 106, 860-870.

Zhang, S. C., Wernig, M., Duncan, I. D., Brustle, O., and Thomson, J. A. (2001). In vitro differentiation of transplantable neural precursors from human embryonic stem cells. Nat. Biotechnol. 19, 1129-1133.

Conflict of Interest Statement: The authors declare that the research was conducted in the absence of any commercial or financial relationships that could be construed as a potential conflict of interest.

Received: 31 January 2013; paper pending published: 24 February 2013; accepted: 30 March 2013; published online: 17 April 2013.

Citation: Ginhoux F, Lim S, Hoeffel G, Low $D$ and Huber T (2013) Origin and differentiation of microglia. Front. Cell. Neurosci. 7:45. doi: 10.3389/fncel. 2013.00045

Copyright () 2013 Ginhoux, Lim, Hoeffel, Low and Huber. This is an openaccess article distributed under the terms of the Creative Commons Attribution License, which permits use, distribution and reproduction in other forums, provided the original authors and source are credited and subject to any copyright notices concerning any third-party graphics etc. 